\title{
Functional Anatomy of the Inferior Longitudinal Fasciculus: From Historical Reports to Current Hypotheses
}

\author{
Guillaume Herbet ${ }^{1,2,3 *}$, Ilyess Zemmoura ${ }^{4,5}$ and Hugues Duffau ${ }^{1,2,3}$ \\ ${ }^{1}$ Department of Neurosurgery, Gui de Chauliac Hospital, Montpellier University Medical Center, Montpellier, France, \\ ${ }^{2}$ INSERM-1051, Team 4, Saint-Eloi Hospital, Institute for Neurosciences of Montpellier, Montpellier, France, ${ }^{3}$ University of \\ Montpellier, Montpellier, France, ${ }^{4}$ Department of Neurosurgery, Tours University Medical Center, Tours, France, ${ }^{5}$ UMR 1253 , \\ iBrain, INSERM, University of Tours, Tours, France
}

OPEN ACCESS

Edited by: Laurent Petit,

Centre National de la Recherche Scientifique (CNRS), France

Reviewed by:

René Martin Müri,

Universität Bern, Switzerland Francesco Latini,

Uppsala University, Sweden

*Correspondence:

Guillaume Herbe

Guillaume.herbet@gmail.com

Received: 26 March 2018

Accepted: 30 August 2018

Published: 19 September 2018

Citation:

Herbet G, Zemmoura I and Duffau H

(2018) Functional Anatomy of the Inferior Longitudinal Fasciculus: From Historical Reports to Current Hypotheses. Front. Neuroanat. 12:77. doi: 10.3389/fnana.2018.00077
The inferior longitudinal fasciculus (ILF) is a long-range, associative white matter pathway that connects the occipital and temporal-occipital areas of the brain to the anterior temporal areas. In view of the ILF's anatomic connections, it has been suggested that this pathway has a major role in a relatively large array of brain functions. Until recently, however, the literature data on these potential functions were scarce. Here, we review the key findings of recent anatomic, neuromodulation, and neuropsychological studies. We also summarize reports on how this tract is disrupted in a wide range of brain disorders, including psychopathologic, neurodevelopmental, and neurologic diseases. Our review reveals that the ILF is a multilayered, bidirectional tract involved in processing and modulating visual cues and thus in visually guided decisions and behaviors. Accordingly, sudden disruption of the ILF by neurologic insult is mainly associated with neuropsychological impairments of visual cognition (e.g., visual agnosia, prosopagnosia, and alexia). Furthermore, disruption of the ILF may constitute the pathophysiologic basis for visual hallucinations and socio-emotional impairments in schizophrenia, as well as emotional difficulties in autism spectrum disorder. Degeneration of the ILF in neurodegenerative diseases affecting the temporal lobe may explain (at least in part) the gradual onset of semantic and lexical access difficulties. Although some of the functions mediated by the ILF appear to be relatively lateralized, observations from neurosurgery suggest that disruption of the tract's anterior portion can be dynamically compensated for by the contralateral portion. This might explain why bilateral disruption of the ILF in either acute or progressive disease is highly detrimental in neuropsychological terms.

Keywords: inferior longitudinal fasciculus, ventral pathway, visual agnosia, semantics, reading, emotion recognition, prosopagnosia, lexical retrieval

\section{INTRODUCTION}

Theinferior longitudinalfasciculus (ILF) is a long-range white matter pathway that primarily connects the occipital lobe of the brain with the anterior temporallobe (ATL). Although the first anatomic description of the ILF dates back to the beginning of the $19^{\text {th }}$ century (Reil, 1812; Burdach, 1822), scientific efforts to better delineate its connective properties (Catani et al., 2002, 2003; Mori et al., 2002; Wakana et al., 2007; Epelbaum et al., 2008; Gomez et al., 2015; 
Latini, 2015; Latini et al., 2017) and identify ILF-mediated brain functions have only recently been fruitful, thanks to parallel advances in diffusion tensor imaging (DTI) and anatomic dissection (Martino et al., 2010, 2013; Sarubbo et al., 2013). Until recently, the ILF's functions were usually inferred by purely anatomic reasoning. For example, the ILF provides critical connections between occipital and anterior temporal areas, both of which are known to contribute to object recognition; despite the absence of substantive behavioral evidence, it has therefore been hypothesized that the ILF has a critical role in this process. This trend is now being reversed, as a broad range of scientific techniques and approaches are being used to study the healthy or damaged brain. However, the knowledge gained over the last decade has not been comprehensively reviewed. This knowledge is nevertheless absolutely vital for the refinement of anatomicfunctional models of behavioral functions in which the ILF may be a critical pathway. Clearly identifying the role of the ILF should also facilitate our comprehension of psychopathologic, neurodevelopmental, and neurodegenerative conditions [e.g., schizophrenia, autism spectrum disorder (ASD), and semantic dementia $(\mathrm{SD})$ ] in which disruption of this tract can lead to cognitive disorders and abnormal behavior.

In the present review, we first summarize data on the topological organization of the ILF; these range from historical reports to the latest DTI and dissection studies that suggest a multilayered organization. We next focus on studies of both brain-damaged and neurologically healthy participants in which the ILF's role in an array of visual-based functions has been highlighted. Alteration of the ILF's connectivity leads to visual agnosia and prosopagnosia, semantic and lexical retrieval difficulties, alexia, and impairments in visual emotion recognition. We also review reports concerning the impact of disruption of the ILF in psychopathologic and other neurologic disorders; these data indicate how the tract may be involved in the pathogenesis of a range of clinical and behavioral symptoms. Lastly, we look at how the ILF (and especially its anterior part) can be dynamically compensated for in certain pathophysiologic situations.

\section{REVIEW CRITERIA}

Literature on the ILF published up to 2017 was accessed by searching open-access Internet and proprietary databases (PubMed, PubMed Central, MEDLINE, Web of Science, and Google Scholar). The search term was "inferior longitudinal fasciculus." Records were screened manually, and only experimental investigations and reviews were selected. Historical reports not referenced in the databases were also selected for review.

\section{ANATOMY}

\section{Historical Descriptions}

Burdach $(1819,1826)$ and Dejerine and Dejerine-Klumpke (1895) provided details of the tract's structure in their important book
"Anatomie des centres nerveux." By this time, scientists had started to use dichromate to harden anatomic specimens, and the invention of the microtome had simplified the preparation of serial sections. The development of these and other histopathologic techniques (notably methods for staining myelin sheaths) and application of Wallerian degeneration had enabled the performance of remarkably accurate analyses long before the advent of MRI and diffusion tractography. Nonetheless, the Dejerines' meticulously detailed description of the ILF was mostly restricted to the core of the tract, i.e., the compact portion of fibers surrounding the inferior and inferior-lateral aspects of the lateral ventricle. According to the Dejerines (Figure 1A), the ILF formed "a kind of sharply bent "gutter" or groove, open at the top and the inside, which receives fibers from the occipital-temporal lobe in its concave projection. [...] Inside the occipital lobe, the inferior wall of the gutter turns in on itself at the top and on the inside. At the base of the cuneus, the two edges of the "gutter" are so close to each other that they join together and transform the bundle into a kind of empty cone, the slender apex of which is located around $2.5 \mathrm{~cm}$ from the occipital pole. It follows that on coronal sections, the ILF is shaped like a relatively irregular, angular ring inside the occipital lobe, and like a sharply bent "gutter" inside the temporal lobe."

In view of the fibers' cortical terminations and orientation, the Dejerines stated that the ILF "sends a great number of fibers to the three temporal convolutions (T1, T2, and T3), the third occipital convolution (O3), and the fusiform and lingual lobules." The Dejerines further affirmed that "the fibers of the ILF originate inside the cortex of the occipital pole and lobe (...) and rapidly come together to form a thin annular fascicle behind the occipital horn $(. .$.$) , whereas fibers originating from the inferior-lateral$ half of the occipital lobe are oriented from back to front along the inferior-lateral edge of the occipital and temporal horns, fibers originating from the superior-lateral part of this lobe are oriented very obliquely downward and forward along the lateral wall of the ventricular atrium, and are all the more oblique when they come from higher regions."

\section{Controversial Aspects}

In their book, the Dejerines disagreed with the descriptions made by Gratiolet (1839), Meynert (1865), and Wernicke (1881), who considered that the ILF was made of projection fibers from the occipital lobe. In contrast, the Dejerines agreed with Sachs' suggestion (in Sachs, 1992) whereby the ILF (referred to as the stratum sagittale externum by Sachs) was composed solely of association fibers. According to the Dejerines, the projection and association fibers in the superior part of the ILF are so intertwined that dissection cannot resolve the problem; the only way to distinguish between the two is to apply the Wallerian degeneration method. The Dejerines also stated that "the inferior portion of the ILF is solely an association pathway." Nonetheless, the same question was raised a century later by Tusa and Ungerleider (1985); via blunt dissections of human and monkey brains, and autoradiography of monkey brain slices, the researchers only found a series of short $U$ fibers connecting the occipital and temporal regions (Figure 1B). Tusa and Ungerleider (1985) therefore disagreed with Sachs' and the 

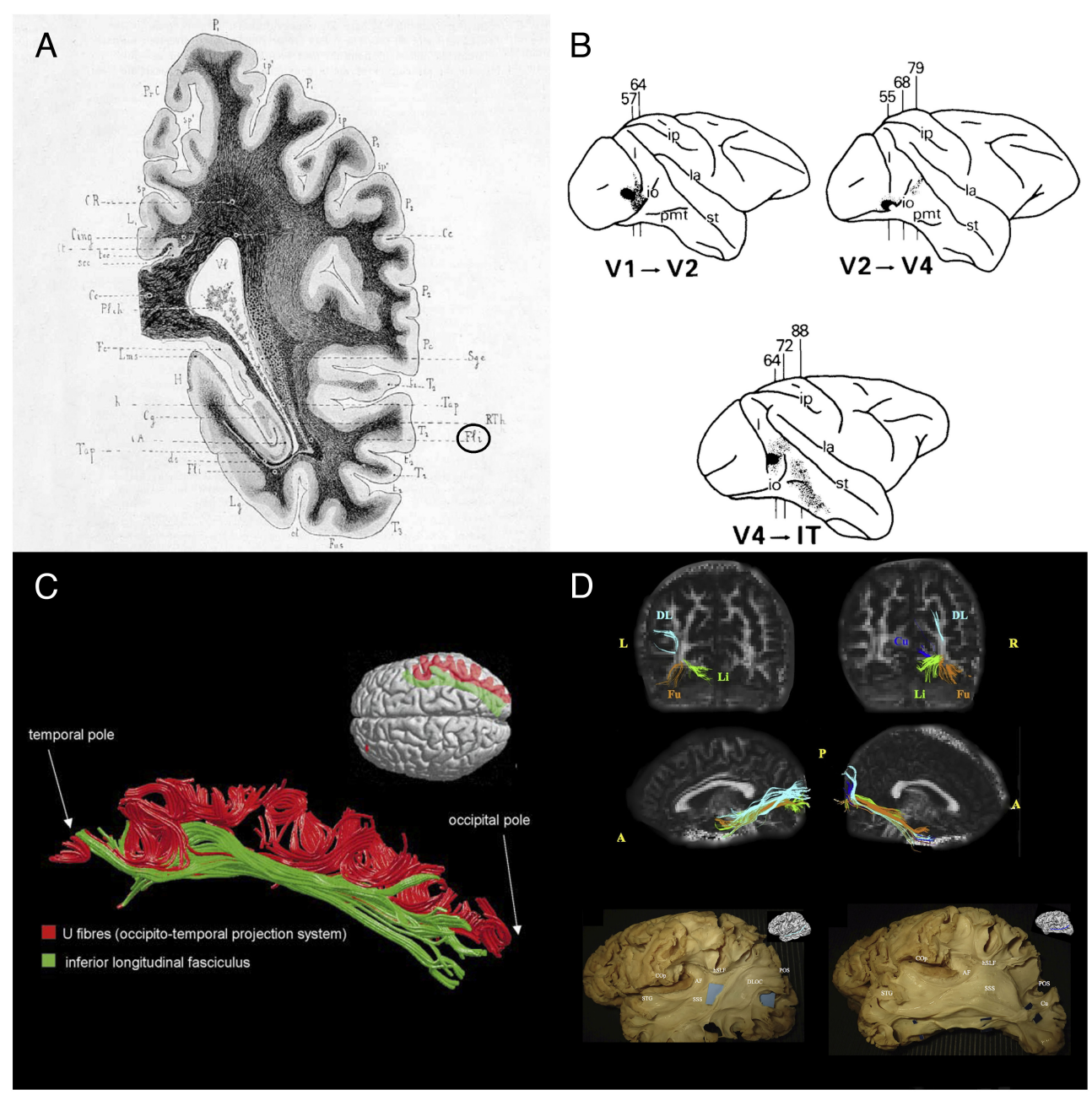

FIGURE 1 | Historical and recent anatomic descriptions of the ILF. (A) A drawing of a coronal section passing through the ventricular atrium posterior to the caudate nucleus, showing the inferior longitudinal fasciculus (Fli) surrounding the optic radiations (RTh), the tapetum fibers (Tap), and the lateral ventricle (VI). From Dejerine's and Dejerine-Klumpke's book "Anatomiedes Centres Nerveux," 1895. Figure 383. (B) Reconstructions of autoradiographic observations. Injection sites and cortical projections in three monkeys are illustrated. Top left panel: injection (in black) into the striate cortex (V1), showing projection to V2 via $U$ fibers and labeled fibers in the internal sagittal stratum that terminate subcortically in more rostral sections. Top right panel: injection into V2, showing projection to V4 via $U$ fibers, labeled fibers in the internal sagittal stratum that terminate subcortically in more rostral sections, and labeled fibers in the tapetum that cross to the contralateral hemisphere. Bottom panel: injection into V4, showing projection to inferior temporal (IT) cortex via $\mathrm{U}$ fibers, labeled fibers in the internal sagittal stratum that terminate subcortically, and labeled fibers in the tapetum that cross to the contralateral hemisphere via the corpus callosum. Tusa and Ungerleider (1985) concluded that the ILF does not have long association fibers. (C) The ILF (in green) and the U-shaped fibers (in red) of the right hemisphere in a single brain dataset. The U-shaped fibers are located laterally to the ILF, and connect the adjacent gyri of the lateral occipitotemporal cortices to form the occipital-temporal projection system from Catani et al. (2003) (D) Subcomponents of the ILF. Top and middle rows: Diffusion tensor tractography of ILF subcomponents in an individual. Top row: a coronal view of the whole course of each segment (from the occipital terminations). Middle row: a sagittal view of a tractographic reconstruction of the four ILF subcomponents on the right side and only three segments on the left side. Bottom row: White matter dissection of the lateral aspect of a left hemisphere, showing the dorsolateral occipital segment (left panel) and the cuneal segment (right panel). Permission to reproduce the figures has been granted. A, anterior; AF, arcuate fasciculus; COp, central operculum; Cu, cuneal segment (blue); DL, dorsolateral occipital segment (turquoise); DLOC, dorsolateral occipital segment; Fu, fusiform segment (orange); hSLF, horizontal segment of the superior longitudinal fasciculus; L, left; Li, lingual segment (green); P, posterior; POS, parieto-occipital sulcus; R, right; SSS, sagittal stratum; STG, superior temporal gyrus.

Dejerines' descriptions, although there is some neurophysiologic evidence (Wilson et al., 1983) of a direct connection between occipital and temporal lobe.

It was not until Catani et al.'s (2003) study using MR diffusion tractography (then a new method for investigating white matter tracts) that the hypothesis of a direct connection between the temporal and occipital lobes was again raised. These tractography experiments (Figure 1C) demonstrated that "in addition to the occipital-temporal projection system [as proposed by Tusa and Ungerleider (1985)], a major associative connection between the occipital lobe and ATL is provided by a fiber bundle whose origin, course, and termination are consistent with classical descriptions of the ILF." This direct connection has been repeatedly identified in further studies using high-resolution 
DTI (e.g., Kamali et al., 2014; Duan et al., 2015; Keser et al., 2016).

\section{Does the ILF Have an Asymmetric, Multilayer Structure?}

Subsequent studies of the ILF (Fernández-Miranda et al., 2008; De Benedictis et al., 2014; Latini, 2015; Latini et al., 2017) based on Klingler's dissection method (a refinement of blunt dissection), providing reliable data on the anatomy of major fiber bundles (Zemmoura et al., 2016) and, in some cases, additional tractography (Latini et al., 2017; Panesar et al., 2018) not only confirmed the classical descriptions of the direct connection between occipital and temporal regions but also sought to detail the subcomponents of this association tract (Figure 1D). The most precise study was performed by Latini et al. (2017), who described marked lateralization of the ILF in the right hemisphere, and the presence of four consistently identified branches: a fusiform branch connecting the fusiform gyrus to the anterior temporal regions (from T1 to T5); a dorsolateral occipital branch connecting the superior, middle and inferior occipital gyri to the anterior temporal regions (from T2 to T4); a lingual branch connecting the lingual gyrus to the anterior part of the middle temporal gyrus (T2); and a minor cuneal branch connecting the cuneus to the anterior mesial temporal gyri $\mathrm{T} 4$ and $\mathrm{T} 5$.

\section{Anatomical Relationships of the ILF With Other White Matter Pathways}

The ILF is in direct contact with five other association tracts: the uncinate fasciculus, the inferior fronto-occipital fasciculus (IFOF), the long and posterior/vertical segments of the arcuate fasciculus and the vertical occipital fasciculus of Wernicke. It has also close relationships with the optic radiations and with the fibers forming the tapetum of the corpus callosum.

Both the uncinate fasciculus and the ILF have cortical projections in anterior temporal structures. They provide an indirect anatomical connection between the posterior temporal and occipital areas, and the frontal lobe. According to some authors, both anatomical connectivities may form an indirect ventral stream for language and semantic processing (Duffau et al., 2013).

The IFOF is also in close relationship with the ILF. Inside the temporal and occipital lobes, the ILF runs more superficial and ventral than the IFOF. Both white matter tracts have cortical terminations in posterior occipito-temporal areas, especially in the fusiform, lingual and lateral occipital cortices.

The long and the posterior segments of the arcuate fasciculus, the vertical occipital fasciculus and the ILF have all four cortical terminations in the posterior part of the inferior temporal gyrus, making this brain area important for direct interactions between the ventral and dorsal streams.

Finally, at the deep aspects of the ILF, inside the temporal lobe, are found the fibers forming the stratum sagittale where pass the IFOF and the middle longitudinal fasciculus cranially, and the optic radiations and the tapetum medially.

\section{Anatomic Maturation}

Diffusion tensor imaging studies of white matter maturation over the lifespan generally suggest that the ILF matures earlier than other association white matter fibers (e.g., the cingulum, the uncinate fasciculus, and the arcuate fasciculus) (Dubois et al., 2008; Lebel et al., 2008; Hasan et al., 2010; Lebel et al., 2012). In humans, the ILF can be identified at the age of three months on fractional anisotropy (FA) maps derived from DTI (Hermoye et al., 2006). Indeed, the ILF is the association tract that shows the earliest and fastest age-related changes in DTI parameters: the FA reaches $90 \%$ of its maximum by the age of 11 years, and the mean diffusivity (MD) falls to its minimum by the age of 20 (Lebel et al., 2008). The age-related increase in FA (a measure of tract integrity) and decrease in $\mathrm{MD}$ are thought to reflect white matter maturation processes (i.e., fiber organization, pre-myelination, and myelination; see Yoshida et al., 2013 and Dubois et al., 2014, for example). This could indicate that the early development of this tract is associated with the rapid maturation of some basic perceptual and cognitive processes (Lebel et al., 2012). These observations are in line with the ILF's putative role in visual cognition (see below), aspects of which are present at birth. Indeed, visual cognition is a key part of early cognitive functioning, and develops rapidly during infancy (Rose et al., 2004). However, it is noteworthy that the ILF and other association tracts may mature later than originally thought. Indeed, the results of a recent longitudinal study showed that the ILF continues to develop during adolescence and is not fully mature until the age of 24 or so (Lebel and Beaulieu, 2011; Lebel and Deoni, 2018).

\section{FUNCTIONS MEDIATED BY THE ILF}

\section{Object Recognition}

In view of the ILF's cortical endpoints in visual occipital and inferior temporal associative areas, this tract is topographically well located to subserve the so-called ventral visual stream (as opposed to the dorsal visual stream) thought to be critical for object recognition (Ungerleider and Haxby, 1994; Milner and Goodale, 1995). In support of this hypothesis, unilateral or (more frequently) bilateral disruption of the ILF following infarction of the posterior cerebral artery (Benson et al., 1974; Albert et al., 1979; Feinberg et al., 1994) or occipitaltemporal hematoma (Kawahata and Nagata, 1989; Meichtry et al., 2017) has been linked to visual agnosia (i.e., the inability to recognize objects, despite the absence of primary visual defects). These neuropsychological findings concur with the results of neuromodulation studies in which "virtual" disruption of the ILF (using direct electrostimulation) in patients undergoing "awake" craniotomy for low-grade glioma caused transient visual hemi-agnosia (Mandonnet et al., 2009; Coello et al., 2013; Gil-Robles et al., 2013). In patients with posterior cortical atrophy (a rare neurodegenerative condition characterized by progressive focal degeneration of the posterior cortex), one observes (i) a decrease in cortical volume in the occipito-temporal areas, and (ii) structural disruption of the ILF (as evidenced by significant increases in mean, parallel 
and transverse diffusivities) (Migliaccio et al., 2012). As a consequence, progressive degeneration of the ILF may well be involved in the pathogenesis of the high-level visual impairments typically observed in these patients, and especially visual agnosia (Benson et al., 1988). In a more indirect argument, children with a developmentally impaired ability to recognize objects also show bilateral disruption in the ILF (as evidenced by low FA compared to age-matched controls) - the extent of which is correlated with the severity of the impairment (Ortibus et al., 2012). Taken as a whole, these findings clearly indicate that (i) the ILF carries signals that are important for object recognition, and (ii) disruption of this pathway can lead to visual agnosia - especially when the disruption extends to both hemispheres.

\section{Face Recognition}

Converging evidence from both positron emission tomography and functional MRI (fMRI) studies suggests that certain cortical regions in the ventral occipital-temporal cortex are part of a "core" face-selective network, i.e., they are more strongly activated by faces than by other classes of stimuli like objects or places (for a comprehensive review, see Grill-Spector et al., 2017). The first of these regions is located in the inferior occipital gyrus (the occipital face area, OFA), whereas the two others are situated more anteriorly in the posterior and middle parts of the fusiform gyrus (the fusiform face area, FFA). Although other regions (especially the ATL) are reportedly face-selective, they are currently considered to belong to the so-called "extended" face network.

Given the cortical anatomies of the "core" and "extended" face networks, it is likely that the ILF and some of the shorter fibers in the occipital-temporal projection system (Tusa and Ungerleider, 1985; Catani et al., 2003) convey critical signals in face perception and recognition. This may especially be the case in the right hemisphere, which is known to have a prominent role in face processing. In fact, the results of two DTI studies of healthy subjects suggest that the ILF indeed carries critical signals for face processing. In the first study, face recognition performance was strongly associated with higher fractional anisotropy (FA) in the anterior part of the right ILF, whereas scene recognition performance tended to be correlated with the FA in the middle and posterior parts of both the left and right ILFs (Tavor et al., 2014). According to the second DTI study, there is a double dissociation between the functions of the right ILF and those of the fornix. More specifically, DTI parameters (including MD and FA) in the ILF (but not in the fornix) were strongly associated with face processing, whereas the same parameters in the fornix (but not in the ILF) were correlated with scene processing (Hodgetts et al., 2015).

If the ILF does indeed have a significant role in face processing, then disruption of this pathway should be associated with impaired face recognition. The best evidence of this relationship has come from studies of patients with prosopagnosia, i.e., in whom face recognition is severely impaired despite normal vision and intelligence. A recent study found that patients with congenital prosopagnosia displayed a notable reduction (relative to healthy subjects) in the microstructural organization of both the ILF and the IFOF on both body sides (Thomas et al., 2009). Importantly, the mean FA values in the right ILF and (to a lesser extent) the right IFOF were inversely correlated with impaired face recognition. In a further study, a patient suffering from progressive prosopagnosia showed fewer streamlines in the right ILF (but not the left ILF or the IFOF) than matched control subjects did (Grossi et al., 2014). However, two other studies found that white matter disruption in the vicinity of the middle FFA (rather than disruption of the entire tract) may be a better predictor of face recognition impairments in individuals with prosopagnosia (Gomez et al., 2015; Song et al., 2015). Lastly, a study revealed that the accuracy of face memory was predicted by the microstructural properties of the right ILF; more specifically, lower FA was associated with better performance (Unger et al., 2016).

In summary, the result studies of healthy individuals and brain-damaged patients suggest strongly that a functional right ILF is crucial for efficient face recognition. However, this hypothesis does not rule out the possible involvement of other white matter connectivities (whether associative or intralobar) in face recognition. Indeed, functional imaging has identified a number of face-selective cortical areas. For example, white matter connections between the right posterior superior temporal sulcus and the temporal pole (both of which belong to the "extended" face network) may convey critical signals for face recognitionperhaps through the fibers in the middle longitudinal fasciculus.

\section{Reading}

Regions in the ventral occipital-temporal cortex have been repeatedly identified as being particularly important in reading processing; this is especially true for the so-called visual word form area (vWFA) located in the lateral occipitotemporal sulcus (between fusiform and inferior temporal gyri), which enables the recognition of word forms (Dehaene et al., 2002; Dehaene and Cohen, 2011). The fact that lesions in this area are known to cause alexia (Hillis et al., 2005; Tsapkini and Rapp, 2010; Turkeltaub et al., 2014) demonstrates the region's causal involvement in reading. Although the anatomic connectivity of the vWFA has not yet been well established (Yeatman et al., 2014), there is some evidence to suggest that the posterior part of the left ILF conveys critical, reading-related visual information from occipital areas to the posterior vWFA. In one study, progressive degeneration of the ILF was observed in a patient who developed pure alexia after surgical resection posterior to the vWFAsuggesting that differentiation of the posterior vWFA is the pathophysiologic cause of reading difficulties (Gaillard et al., 2006; Epelbaum et al., 2008). This hypothesis was supported by a recent case report on the advent of pure alexia following surgeryrelated disruption of the left posterior ILF (Zemmoura et al., 2016).

In line with the hypothesis whereby the ILF subserves the semantic/orthographic reading pathway, other data suggest that the tract is involved in reading comprehension. For example, inter-individual variations in the microstructural properties of both the left and right ILFs in people with normal intelligence are correlated with word reading fluency and reading comprehension (Horowitz-Kraus et al., 2014). This agrees with the fact that 
difficulties in reading comprehension were found to be associated with abnormalities of the right ILF in adolescents born preterm (Feldman et al., 2012) and abnormalities of the left ILF in poor decoders (Arrington et al., 2017). Lastly, these findings are consistent with the observation that the rate of maturation of the ILF covaries with children's reading abilities (Yeatman et al., 2012).

\section{Lexical and Semantic Processes}

The ILF has many connections to the ATL; it has been suggested that the latter's ventrolateral aspect ATL acts as a transmodal semantic hub (Visser et al., 2010; Binney et al., 2012; Lambon Ralph, 2014; Rice et al., 2015; Lambon Ralph et al., 2017). In view of this anatomic background, it has been suggested that along with other ventral white matter tracts [especially the IFOF and the uncinate fasciculus (UF)], the ILF acts as a major white matter pathway for the so-called semantic ventral stream (Saur et al., 2008; Turken and Dronkers, 2011; Duffau et al., 2013; Moritz-Gasser et al., 2013; Dick et al., 2014; Almairac et al., 2015). However, the ILF's exact role in semantic cognition has not been yet firmly established. In fact, most of the evidence comes from patients with SD (Agosta et al., 2010; Acosta-Cabronero et al., 2011) or the semantic variant of primary progressive aphasia (svPPA), in whom the ILF is disrupted (Mandelli et al., 2014; D'Anna et al., 2016; Tu et al., 2016). Progressive degeneration of the ILF may account (at least in part) for the semantic impairments typically observed in these patients. However, to the best of our knowledge, only a few studies have revealed clear associations between changes in DTI parameters in the ILF and impaired semantic or lexicosemantic abilities. For example, a studies of patients with PPA highlighted significant positive correlations between performance in behavioral tasks probing semantic association abilities and word comprehension on one hand, and FA in the anterior left ILF on the other (Mandelli et al., 2014). In another study, significant correlations were found between some DTI metrics in the ILF [especially FA and radial diffusivity $(\mathrm{RD})]$ and two semantic factors (semantic richness in the left ILF only, and semantic features in the left and right ILFs). This finding suggests that some of the lexicosemantic impairments observed in these patients may be partly explained by structural disruption of the ILF (Marcotte et al., 2017). Similar observations were made in patients with $\mathrm{SD}$; $\mathrm{MD}$ in the left ILF was negatively correlated with worse performance in a lexicosemantic task (Agosta et al., 2010).

Two very recent studies of healthy individuals have provided a better understanding of the types of semantic processes that may be distributed through the ILF. In the first study, inter-individual variability in the microstructural properties of both the ILF and the UF was found to be predictive of successful word-learning; the significant negative correlation between performance and RD suggested that connectivities of the ILF and the UF are involved in the acquisition of novel word-to-meaning mappings, and thus in semantic learning (Ripollés et al., 2017). In the second study, the combined use of constrained spherical deconvolution-based tractography and behavioral assessments revealed a double correlational dissociation: inter-individual variability in the microstructural properties of the ILF was correlated with the richness of semantic autobiographical memory (i.e., a negative correlation between $\mathrm{MD}$ and performance), whereas inter-individual variability in the microstructural properties of the fornix was correlated with the richness of episodic memory (i.e., a positive correlation between FA and performance) (Hodgetts et al., 2017). Hodgetts et al. (2017) pointed out that this double dissociation is reminiscent of observations in patients with SD; although their semantic autobiographical memory is impaired, their episodic memory is relatively unaffected.

Other experimental evidence suggests that the left ILF is involved in other language processes-lexical retrieval, in particular. In a large-scale neuropsychological study of 110 patients having undergone a surgical resection for diffuse lowgrade glioma (DLGG), residual tumor infiltration in the left ILF was found to be a strong predictor of permanent impairments in lexical retrieval (Herbet et al., 2016b). This result fits well with the observation whereby disruption of the left ILF in stroke patients (estimated as the likelihood of fiber tract disconnection) was predictive of naming impairments for certain non-unique categories (i.e., animals, fruits and vegetables) (Mehta et al., 2016). More anecdotally, a recent neurosurgical case study found that tumor invasion of the left ILF was associated with naming impairments (Shinoura et al., 2010).

\section{Emotions and Related Processes}

By virtue of the ILF's connections with both the visual cortex and the amygdala, this tract is conceptually well suited to the integration of visual and emotional processes within the cortical affective network. In fact, the first evidence for this involvement was reported in the 1980s and 1990s; three patients with occipital-temporal lesions extending to the ILF were described as suffering from a syndrome called visual hypoemotionality, defined as a "modality-specific inability to become aroused by visual cues" and which was accompanied by feelings of "unreality or detachment" (Bauer, 1982; Habib, 1986; Lopera and Ardila, 1992; Sierra and Berrios, 1998; Ross, 2008; Perez et al., 2014). At the time, this neuropsychological disturbance was interpreted as a "visuolimbic disconnection syndrome." Recently, a case report on a fourth patient with a right parietal-temporal-occipital lesion has been published. Disruption of the patient's right ILF was found to be significantly associated with low numbers and volumes of streamlines (compared with matched neurologically healthy controls). This finding adds support to the concept in which disruption of the amygdalo-occipital pathway may be the pathophysiologic basis of visual hypoemotionality (Fischer et al., 2016).

Other lines of inquiry suggest that the ILF and other ventral tracts may be particularly important for the recognition of facial emotions. The most robust findings in this respect come from two large-scale neuropsychological studies. In the first study ( $n=104$ patients), the extent to which the IFOF and/or the ILF were disrupted (with regard to lesion volume) was found to be strongly predictive of inability to identity facial emotions (Philippi et al., 2009). These results were confirmed 
in a second study of patients $(n=42)$ suffering from moderateto-severe traumatic brain injury (Genova et al., 2015). Indeed, impaired performance in the Facial Emotion Identification Test was significantly and negatively correlated with several DTI parameters (notably axial diffusivity (AD), MD, and $\mathrm{RD}$ ). On the same lines, a study of patients with amyotrophic lateral sclerosis found that difficulties in recognizing negative emotions were linked to microstructural changes (as evidenced by low FA) in both the right ILF and IFOF (Crespi et al., 2014). These studies' general findings are in agreement with a recent report showing that the microstructure of both tracts predicts the accuracy with which facial emotions are discriminated (i.e., a negative correlation between performance and AD) (Unger et al., 2016). This also agrees with the fact that individuals who discriminate facial emotions (especially angry faces) more rapidly are those with a higher degree of macrostructural organization in the right ILF (Marstaller et al., 2016). Lastly, a study of people with antisocial personality disorder (a psychologic condition in which emotion regulation and facial recognition may be impaired), the microstructural properties of the left ILF (as measured by the RD) and two other white matter tracts were strongly correlated with risk behavior (Jiang et al., 2017).

\section{Visual Memory}

A study of a 47-year-old patient with a tumor that had mainly invading the white matter of the temporal lobe suggested that the ILF may be involved in visual memory (Shinoura et al., 2007). The patient showed poor visual memory, as assessed by the revised version of the Wechsler Memory Scale. DTI evidenced the partial disconnection of the right ILF. This finding fits well with the proposed role of the ILF in relaying visually learned information during haptic processing (Lee Masson et al., 2017a) and in visual-haptic processing more generally (Lee Masson et al., 2017b).

\section{Summary}

Taken as a whole, the studies reviewed here indicate that the ILF may be involved a broad range of brain functions concerning the visual modality, including object, face and place processing, reading, lexical and semantic processing, emotion processing, and visual memory. The data suggest that the ILF is a multi-functional white matter pathway that is mainly involved in visually guided behavior. Although some of the abovementioned processes are markedly biased toward a particular hemisphere (e.g., the right ILF in face processing and left ILF in lexical processing and reading), other appears to be bilateral (e.g., object recognition). Further research must now better delineate the ILF's exact state of involvement in each hemisphere.

It is also noteworthy that only a few studies have focused on the ILF's functions. Much of the experimental evidence has been derived by studying the correlation between DTI scalars and behavior in healthy subjects. Accordingly, causal and converging evidence is still needed to confirm and generalize most of the results described in this section.

\section{DISRUPTION OF THE ILF IN SCHIZOPHRENIA, ASD, AND OTHER NEUROLOGIC CONDITIONS}

\section{Schizophrenia and Related Psychopathologic Disorders}

Several lines of evidence suggest that white matter abnormalities are central in the pathogenesis of schizophrenia, and may result from impaired myelination and/or oligodendroglial function (Davis et al., 2003). Although these changes are usually described as (i) being widespread in both early- and late-onset forms of schizophrenia (Douaud et al., 2007; Price et al., 2007; Kanaan et al., 2009; Lee et al., 2013; Kelly et al., 2017) and (ii) concerning all types of white matter connections, recent metaanalyses suggest that certain white matter tracts are particularly compromised. This is especially the case for white matter tracts forming part of the frontotemporal connectivity (i.e., the UF, arcuate fasciculus, cingulum, and IFOF) or interhemispheric connectivity (the corpus callosum and anterior commissure) (Kubicki et al., 2005; Kelly et al., 2017). Some studies have linked these patterns of white matter disruptions to the neuropsychological impairments typically observed in patients with schizophrenia (impaired psychomotor speed, working memory, and executive functions, among others) (Lee et al., 2013; Kochunov et al., 2017).

Although structural disruption of the ILF is apparently less frequent than structural disruption of other white matter tracts, some studies suggest that ILF is only damaged in patients showing specific patterns of clinical symptoms (Ashtari et al., 2007; Cheung et al., 2008; Friedman et al., 2008; Phillips et al., 2009). This is consistent with the fact that patients with schizophrenia do not generally suffer from abnormal cognitive processes potentially related to alterations in the neural systems mediated by the ILF.

In a recent study, the mean DTI metrics (especially the FA) in the left ILF (but not the right ILF) were significantly lower in adolescents with schizophrenia than in healthy controls (Ashtari et al., 2007). Importantly, the investigators compared two subgroups of patients with or without a history of visual hallucinations. Ashtari et al. found that the mean FA in the left ILF was lower in the subgroup with a history of visual hallucinations than in the subgroup without history of visual hallucinations - suggesting that disruption of ILF may be a neuropathologic basis for visual hallucinations. A second study of 23 patients confirmed the structural disruption of ILF (on both the left and right), and highlighted a negative correlation between the mean FA in the right ILF and the severity of schizophrenic symptoms (Phillips et al., 2009). This finding was recently confirmed in a study of patients with early-course schizophrenia (Seitz et al., 2016).

Along the same lines, patients with 22q11.2 deletion syndrome (a genetic neurodevelopmental disorder associated with a range of physical, physiologic, neuropsychological, and psychiatric impairments) also display abnormal white matter connectivity. Importantly, individuals with 22q11.2 deletion syndrome have an elevated risk of developing schizophrenia, with 
an incidence of approximately 30\%. Overall, individuals with $22 \mathrm{q} 11.2$ deletion syndrome appear to have the same patterns of white matter alterations as patients with schizophrenia (Dennis and Thompson, 2013; Scariati et al., 2016; Olszewski et al., 2017; Padula et al., 2017). Interestingly, ILF abnormalities have been consistently identified, and a recent study based on DTI and machine-learning classification (a support vector machine) not only confirmed that the ILF is one of the most affected tracts in 22q11.2 syndrome but also showed that the ILF's DTI parameters are correlated with prodromal symptoms of psychosis; this suggests that disruption of the tract may increase the likelihood of developing schizophrenia-like disorders (Tylee et al., 2017). Among the broad array of neuropsychological disorders typically present in patients with 22q11.2 deletion syndrome, impairments of social cognition (including theory of mind and empathy) are rather common (Weinberger et al., 2016; Norkett et al., 2017; Olszewski et al., 2017), and were recently described as a powerful predictor of psychotic symptoms in this population (Jalbrzikowski et al., 2014). Given that the ILF is known to connect regions required for social cognition (such as the amygdala and fusiform gyrus), it is possible that abnormal DTI parameters in the ILF reflect a pathophysiologic mechanism accounting for (at least in part) social cognition disturbances and psychotic symptoms in this specific patient population. However, this hypothesis has yet to be specifically tested.

\section{Autism Spectrum Disorder}

Disruption of the structural connectome is one of the most frequently reported features of ASD. Indeed, scientific research has repeatedly identified anomalies in the microstructural organization of associative and inter-hemispheric white matter tracts in this patient population. Indeed, fiber tract disruption is now considered to be an integral part of the neural phenotype in ASD. However, the hypothesis whereby patients with ASD present with widespread, severe alterations of white matter pathways has been challenged. For example, recent work demonstrated that most of the white matter changes observed in ASD might be artifacts caused by the patient's head motiona variable that had not been carefully controlled for in most of the literature studies (Koldewyn et al., 2014). However, Koldewyn et al.'s (2014) study also showed that the right ILF was the only tract found unambiguously to be damaged after controlling for the imaging quality. From a clinical perspective, this general finding fits very well with the fact that the right ILF is known to be a critical white matter tract for face and emotion processing (see above) and that impaired face and emotion recognition are neuropsychological markers of patients with ASD (Dawson et al., 2004; Weigelt et al., 2012). The selective disruption of the right ILF in ASD was recently confirmed (Boets et al., 2018). Interestingly, disruption to the ILF (as evidenced by lower FA) was correlated with slower performance in a visual search task. This finding is consistent with the ILF's known role in visual cognition. Lastly, it is noteworthy that autistic patients with poor language skills display lower FA in the posterior part of the left ILF than autistic patients with moderate to strong language skills (Naigles et al., 2017), and that autistic traits in the non-clinical population correlate with the microstructure of the left ILF (i.e.,
FA values were positively correlated with the autism-spectrum quotient) (Bradstreet et al., 2017).

\section{Summary}

In the above section, we reviewed evidence showing that disruption of the ILF is associated with specific patterns of neuropsychological or clinical symptoms in certain patient populations. In particular, ILF dysfunction may be involved in the pathogenesis of psychotic symptoms in both schizophrenia and 22q11.2 deletion syndrome, and may have a role in the occurrence of the social cognition impairments that characterize both of these disorders. However, the link between ILF dysfunction, behavioral outcomes, and social cognition impairments remains unclear and must be specifically addressed in future studies; ideally, a comprehensive battery of neuropsychological tests should be used to assess the different aspects of social cognition.

In accordance with the ILF's putative functions, our review of the literature suggested that disruption of this tract in ASD can be associated with impaired visual perception and/or poor language skills. Nonetheless, the correlational evidence is relatively dispersed and must be confirmed in subsequent research. Our review raises a number of other interesting ideas, however. For example, it would especially useful to assess to what extent the impairments in face identification and emotion recognition observed in ASD are attributable to anomalies in the ILF-especially in the right hemisphere.

Lastly, the evidence reviewed here suggests that epilepsyrelated dysfunction of the ILF may be a pathophysiologic correlate of a number of cognitive impairments in patients with TLE. However, the data are scarce, and little is presently known about the neuropsychological consequences of disruption of the ILF in this form of epilepsy. A more comprehensive assessment of this putative link might tell us more about the ILF's functions in normal (non-clinical) circumstances.

\section{PLASTICITY OF THE ILF}

As DLGG frequently affects structures in the ATL and thus the underlying connectivity (Duffau and Capelle, 2004; Herbet et al., 2016a), the anterior part of the ILF is often targeted for resection during "awake surgery" with stimulation mapping. However, axonal stimulation studies have failed to identify a role of this pathway in verbal language and semantics-two cognitive domains that are usually mapped and monitored in the operating theater (Mandonnet et al., 2007). Although these negative results should not be construed as evidence that the ILF is not (or only slightly) involved in these functions, they do suggest that ILF functions may be dynamically compensated for by other structures -especially since DLGG is known to induce an efficient neuroplastic response by the brain (Duffau, 2005; Mandonnet et al., 2007; Herbet et al., 2016b). This kind of interpretation may explained why patients with unilateral damage to the ATL (e.g., following a vascular stroke or surgical resection for a tumor or epilepsy) show only mild to moderate impairments in semantic memory (Lambon Ralph et al., 2010), even when the ATL is 


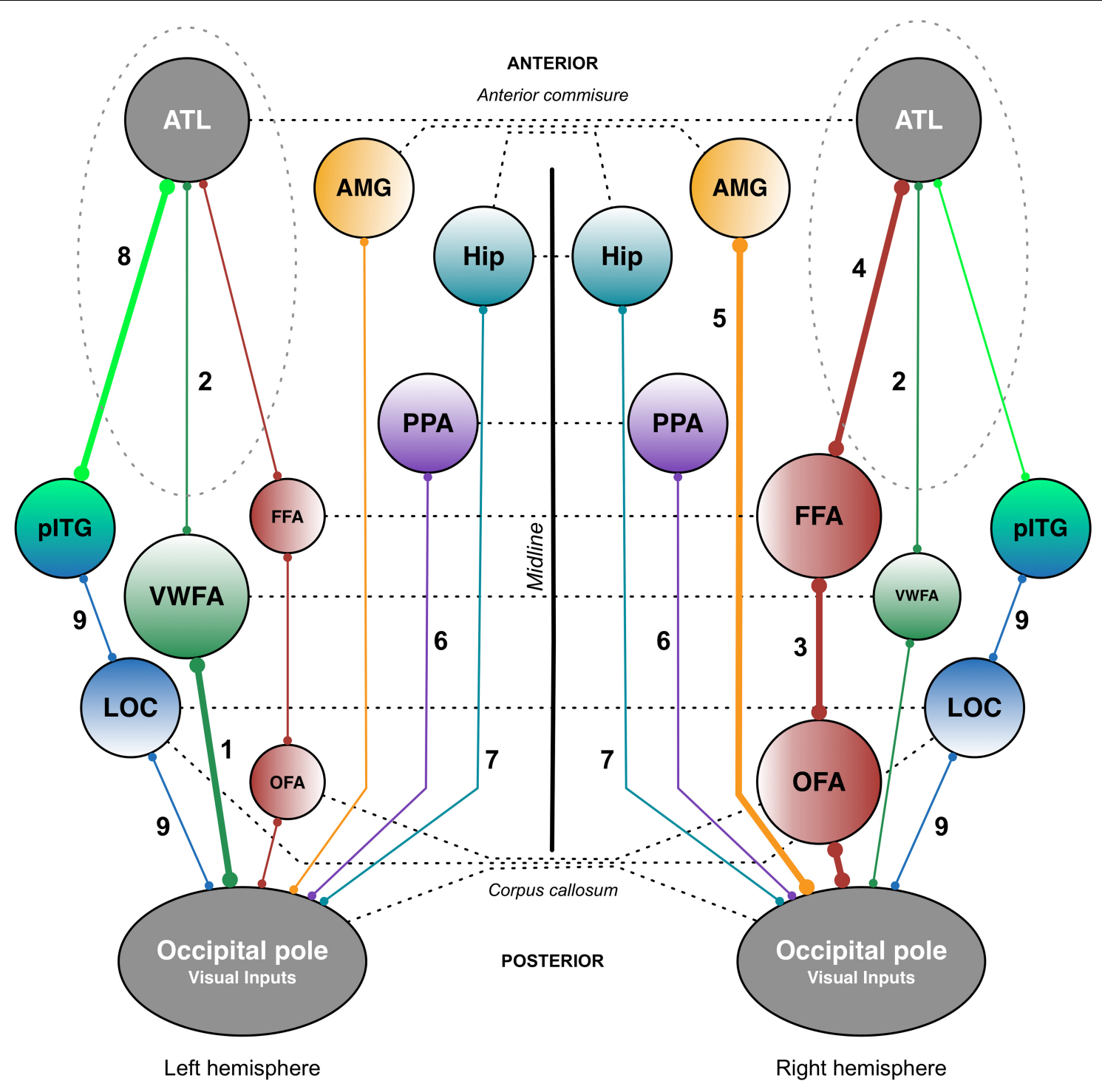

\section{Face perception network \\ Emotion recognition/valuation network \\ Object recognition network \\ Visual memory network}

$\bigcirc$ reading network

Scene perception network

Semantic network (and lexical retrieval in the left hemisphere)

$\bullet$ ILF fibers

.... Inter-hemispheric fibers $\therefore .$. functionally compensable in case of unilateral damage

FIGURE 2 | Putative functional pathways supported by the short and long fibers of the ILF. This schematic summary is derived from the recent literature data (mainly neuropsychological studies) on the ILF's functions. Functional pathways that are biased toward a particular hemisphere are represented by thicker lines and larger circles. The neuropsychological syndromes in the event of disruption are as follows: (1) pure alexia; (2) reading comprehension; (3) apperceptive prosopagnosia; (4) associative prosopagnosia; (5) impairments in emotion recognition or hypoemotionality; (6) scene perception impairments; (7) visual memory impairments; (8) semantic and/or lexical retrieval impairments; and (9) visual agnosia. AMG: amygdala; ATL: anterior temporal lobe; FFA: fusiform face area; Hip: hippocampus; LOC, lateral occipital cortex; OFA: occipital face area; pITG: posterior inferior temporal gyrus; PPA, parahippocampal place area; vWFA, visual word form area.

thought to be critical for this function. It is most likely that both the left and right ATLs have critical roles in semantic memory, and that this massive bilateral organization makes the semantic system more resistant to damage (Lambon Ralph et al., 2010; Rice et al., 2015). Indeed, the contralateral (undamaged) ATL may functionally compensate for the damaged ATL. In the event of bilateral damage to the ATL (as seen in neurodegenerative conditions), marked semantic disorders may appear. The same reasoning might apply to the ILF, which has dense cortical terminations in the ATL. 
In this respect, a recent case study of a patient suffering from multifocal DLGG has provided a better understanding of potential plasticity of the ILF (Corrivetti et al., 2017). The patient underwent two operations. The first operation concerned the right occipital-temporal cortex, including the fusiform and inferior occipital gyri, and the ILF. The second operation (performed one year later) concerned the left anterior temporalinsular cortex, including the anterior ILF. Despite surgical resection of the OFA, the FFA and the ILF, the first operation did not lead to prosopagnosia. In contrast, the second operation caused severe, permanent prosopagnosia. These observations suggest that the face perception network (which is classically biased toward the right hemisphere) was reorganized within the left hemisphere, leading to prosopagnosia only when the left ILF was resected.

Along the same lines, a recent study showed that axonal stimulation of the anterior-to-middle part of the left ILF systematically induced lexical retrieval difficulties during a picture-naming task (i.e., anomia) but only when the temporal pole was not damaged by the tumor (i.e., when the pole was damaged, no impairments were evoked) (Herbet et al., 2018). As well as having confirmed that the left ILF is involved in lexical access, this finding suggests that the information broadcasted by this tract can be rerouted along alternative pathways when progressive tumor infiltration of the temporal pole prompts the latter to abandon its function via progressive functional compensation.

Although disruption of ILF may be compensated for under certain pathophysiologic circumstances, it may also serve as the basis for functional recovery in the event of partial damage. In a kurtosis-based tractography study, it was shown that intensive language rehabilitation (based on confrontation naming) reinforced the microstructural organization of the left ILF. Furthermore, this language rehabilitation was associated with a significant reduction in the naming error rate (i.e., a negative correlation between mean kurtosis and the frequency of semantic paraphasia), suggesting that therapy-induced structural plasticity of the left ILF might be the physiologic basis of semantic recovery in stroke patients (McKinnon et al., 2017).

Lastly, a recent study in neurologically intact participants showed that learning Morse code improves the microstructural organization of the left ILF and suggested that the acquisition of a new language skill is underpinned by the neuroplastic potential of this ventral tract (Schlaffke et al., 2017). In the latter study, the mean FA in the left ILF increased significantly between the preand post-learning periods, and the increase was correlated with behavioral performance.

TABLE 1 | Summary of the functional anatomy of the ILF: a multilayered/multifunctional white matter tract.

\begin{tabular}{|c|c|c|c|c|c|}
\hline Function & $\begin{array}{l}\text { Neuropsychological } \\
\text { syndrome }\end{array}$ & Layer* & Lateralization & Pathologies involved & Main references \\
\hline \multirow[t]{3}{*}{ Face recognition } & Prosopagnosia & $\begin{array}{l}\text { Fusiform and lingual } \\
\text { branches }\end{array}$ & Right & Congenital prosopagnosia & $\begin{array}{l}\text { Thomas et al., 2009; Grossi } \\
\text { et al., } 2014\end{array}$ \\
\hline & & & & Autism spectrum disorder & $\begin{array}{l}\text { Koldewyn et al., 2014; Dawson } \\
\text { et al., 2004; Boets et al., } 2018\end{array}$ \\
\hline & & & & Temporal lobe epilepsy & $\begin{array}{l}\text { Drane et al., 2013; Benke et al., } \\
2013\end{array}$ \\
\hline \multirow[t]{4}{*}{ Object recognition } & $\begin{array}{l}\text { Impaired scene } \\
\text { perception }\end{array}$ & Fusiform branch & Bilateral & Healthy volunteers & $\begin{array}{l}\text { Tavor et al., 2014; Hodgetts } \\
\text { et al., } 2015\end{array}$ \\
\hline & Visual agnosia & Dorsolateral branch & Bilateral & Stroke, hematoma, & $\begin{array}{l}\text { Benson et al., 1974; Meichtry } \\
\text { et al., } 2017\end{array}$ \\
\hline & & & & Glioma awake surgery & $\begin{array}{l}\text { Mandonnet et al., 2009; Coello } \\
\text { et al., } 2013\end{array}$ \\
\hline & & & & Posterior cortical atrophy & Ortibus et al., 2012 \\
\hline $\begin{array}{l}\text { Emotions and related } \\
\text { processes }\end{array}$ & Hypoemotionality & $\begin{array}{l}\text { Cuneal and fusiform } \\
\text { branches }\end{array}$ & Left & $\begin{array}{l}\text { Schizophrenia, 22q11.2 } \\
\text { deletion syndrome }\end{array}$ & $\begin{array}{l}\text { Ashtari et al., 2007; Tylee et al., } \\
2017\end{array}$ \\
\hline Visual memory & Impaired visual memory & Cuneal branch & Right & Glioma & Shinoura et al., 2007 \\
\hline \multirow[t]{4}{*}{$\begin{array}{l}\text { Lexical/semantic } \\
\text { processes }\end{array}$} & $\begin{array}{l}\text { Impaired } \\
\text { semantic/lexical } \\
\text { retrieval }\end{array}$ & $\begin{array}{l}\text { Dorsolateral and } \\
\text { fusiform branches }\end{array}$ & Left / Bilateral & Temporal lobe epilepsy & $\begin{array}{l}\text { Riley et al., 2010; McDonald } \\
\text { et al., } 2014\end{array}$ \\
\hline & & & & Glioma & $\begin{array}{l}\text { Saur et al., 2008; Duffau et al., } \\
\text { 2013; Herbet et al., 2016a,b }\end{array}$ \\
\hline & & & & Primary progressive aphasia & $\begin{array}{l}\text { Mandelli et al., 2014; Tu et al., } \\
2016\end{array}$ \\
\hline & & & & Healthy volunteers & $\begin{array}{l}\text { Ripollés et al., 2017; Hodgetts } \\
\text { et al., } 2017\end{array}$ \\
\hline \multirow[t]{2}{*}{ Reading } & Pure alexia & Dorsolateral branch & Left & Stroke, surgical injury & $\begin{array}{l}\text { Epelbaum et al., 2008; } \\
\text { Zemmoura et al., } 2016\end{array}$ \\
\hline & Reading disorders & Fusiform branch & Bilateral & Prematurity, poor readers & $\begin{array}{l}\text { Horowitz-Kraus et al., 2014; } \\
\text { Arrington et al., } 2017\end{array}$ \\
\hline
\end{tabular}

*Deduced from cortical connections, tractographic studies, or surgical descriptions. 


\section{FUTURES DIRECTIONS AND CONCLUSION}

Although the investigation of the ILF is still in its infancy, the available literature data nevertheless suggests that this white matter tract mainly supports visual functions; indeed, disruption of the ILF is associated with an array of neuropsychological syndromes that involve the visual modality. The findings reviewed here also suggest that the ILF has a multilayered functional organization (see Figure 2 for a schematic illustration), which fits well with the tract's many known or supposed cortical connections. Although some functions of the ILF appear to be relatively lateralized (e.g., reading in the left hemisphere, and face perception in the right hemisphere), a few reports suggest that the anterior part can be dynamically compensated for by the contralateral part. This would explain why bilateral disruption of the ILF appears to be an important feature in the emergence of severe neuropsychological impairments, as is notably the case in neurodegenerative diseases (e.g., SD and PPA) that typically affect the two hemispheres (albeit asymmetrically). Abnormalities in the ILF appear also to be an important determinant of cognitive and behavioral disturbances in certain psychopathologic or neurodevelopmental disorders, such as ASD or schizophrenia.

In general, one must bear in mind that few studies have directly investigated the relationships between the ILF's microstructural properties and behavioral functions in both healthy and brain-damaged patients. Hence, most of the findings reported to date need to be confirmed experimentally by applying (for example) a variety of methodological approaches to generate converging evidence. Furthermore, many of the studies reviewed here suffered from methodological limitationssome of which are specific to DTI methods. These DTI-related limitations (including poor-quality data, limited statistical power, the use of simplistic models of white matter organization, failure to control for cofounding variables (e.g., head motion and sociodemographic variables) and the quasi-exclusive use of FA as measure of tract integrity) have recently been comprehensively reviewed by Wang et al. (2018). Other DTI-related limitations (but which also apply to lesion-mapping functional studies of white matter tracts) include the use of a limited range of behavioral tasks and the lack of control tasks, which prevents one from probing a tract's specific contribution to a given function.

The current review identified a certain number of subjects for further investigation. Firstly, in most of the studies reviewed here, the ILF was considered to be a single-layer white matter

\section{REFERENCES}

Acosta-Cabronero, J., Patterson, K., Fryer, T. D., Hodges, J. R., Pengas, G., Williams, G. B., et al. (2011). Atrophy, hypometabolism and white matter abnormalities in semantic dementia tell a coherent story. Brain 134, 2025-2035. doi: 10.1093/brain/awr119

Agosta, F., Henry, R. G., Migliaccio, R., Neuhaus, J., Miller, B. L., Dronkers, N. F., et al. (2010). Language networks in semantic dementia. Brain 133, 286-299. doi: 10.1093/brain/awp233 tract. However, the results of most recent anatomic dissection and DTI studies (e.g., Latini et al., 2017; Panesar et al., 2018) suggest that this occipitotemporal tract has at least four layers, all of which can be consistently detected in all healthy subjects. However, it is not yet clear how these four layers relate to specific cognitive, emotional or behavioral functions. For example, one might expect the fusiform branch (which connects the fusiform gyrus and the ATL) to be involved in face processing. Likewise, the cuneal branch's cortical terminations in both the cuneal cortex and temporal-medial structures suggest that it conveys critical information for emotion processing (see Table $\mathbf{1}$ for a tentative summary of the ILF's layers possible functions). These hypotheses could be tested by using DTI to track each of the four layers of the ILF and by testing specific anatomic-functional correlations in both healthy and brain-damaged patients. Secondly, it was mentioned above that some functions potentially subserved by the ILF appear to be at least partially lateralized. However, to the best of our knowledge, the relationship between the ILF's degree of anatomic lateralization and the tract's specific functions has never been examined. This type of relationship has been demonstrated for other connective tracts and functions, such as branch II of the superior longitudinal fasciculus and spatial cognition (Thiebaut de Schotten et al., 2011). One can legitimately speculate that the right anatomic asymmetry of the ILF [as described by Latini et al. (2017)] relates to face processing. Lastly, combining fMRI, DTI, and behavioral assessments appears to be a promising avenue for disentangling the differential functional roles of the white matter tracts forming the ILF. Indeed, task-related functional activations can serve as seeds for tractography and thus help to identify specific, detailed anatomic-functional correlations between the tracked fibers and behavioral profiles. This methodology has been successfully used to highlight the involvement of basal temporal white matter tracts in face processing and prosopagnosia (Gomez et al., 2015).

In conclusion, the current review is the first to have provided general principles governing the anatomic and functional organization of the ILF. Although this knowledge is still incomplete and must be greatly extended, it may nevertheless form a solid basis for future investigations of the tract's role in neurocognitive networks.

\section{AUTHOR CONTRIBUTIONS}

GH, IZ, and HD drafted, revised, and approved the final manuscript.

Albert, M. L., Soffer, D., Silverberg, R., and Reches, A. (1979). The anatomic basis of visual agnosia. Neurology 29, 876-876.

Almairac, F., Herbet, G., Moritz-Gasser, S., de Champfleur, N. M., and Duffau, H. (2015). The left inferior fronto-occipital fasciculus subserves language semantics: a multilevel lesion study. Brain Struct. Funct. 220, 19831995. doi: 10.1007/s00429-014-0773-1

Arrington, C. N., Kulesz, P. A., Juranek, J., Cirino, P. T., and Fletcher, J. M. (2017). White matter microstructure integrity in relation to reading proficiency th. Brain Lang. 174, 103-111. doi: 10.1016/j.bandl.2017.08.002 
Ashtari, M., Cottone, J., Ardekani, B. A., Cervellione, K., Szeszko, P. R., Wu, J., et al. (2007). Disruption of white matter integrity in the inferior longitudinal fasciculus in adolescents with schizophrenia as revealed by fiber tractography. Arch. Gen. Psychiatry 64, 1270-1280. doi: 10.1001/archpsyc.64.11.1270

Bauer, R. M. (1982). Visual hypoemotionality as symptom. Arch. Neurol. 39, 702-708. doi: 10.1001/archneur.1982.00510230028009

Benke, T., Kuen, E., Schwarz, M., and Walser, G. (2013). Proper name retrieval in temporal lobe epilepsy: naming of famous faces and landmarks. Epilepsy Behav. 27,371-377. doi: 10.1016/j.yebeh.2013.02.013

Benson, D. F., Davis, R. J., and Snyder, B. D. (1988). Posterior cortical atrophy. Arch. Neurol. 45, 789-793. doi: 10.1001/archneur.1988.005203101 07024

Benson, D. F., Segarra, J., and Albert, M. L. (1974). Visual agnosia-prosopagnosia: a clinicopathologic correlation. Arch. Neurol. 30, 307-310. doi: 10.1001/archneur. 1974.00490340035007

Binney, R. J., Parker, G. J., and Ralph, M. A. L. (2012). Convergent connectivity and graded specialization in the rostral human temporal lobe as revealed by diffusion-weighted imaging probabilistic tractography. J. Cogn. Neurosci. 24, 1998-2014. doi: 10.1162/jocn_a_00263

Boets, B., Van Eylen, L., Sitek, K., Moors, P., Noens, I., Steyaert, J., et al. (2018). Alterations in the inferior longitudinal fasciculus in autism and associations with visual processing: a diffusion-weighted MRI study. Mol. Autism 9:10. doi: 10.1186/s13229-018-0188-6

Bradstreet, L. E., Hecht, E. E., King, T. Z., Turner, J. L., and Robins, D. L. (2017). Associations between autistic traits and fractional anisotropy values in white matter tracts in a nonclinical sample of young adults. Exp. Brain Res. 235, 259-267. doi: 10.1007/s00221-016-4791-5

Burdach, K. F. $(1819,1826)$. Vom Baue und Leben des Gehirns. Leipzig: Dyk.

Burdach, K. F. (1822). Von Baue und Leben des Gehirns. Leipzig: Dykschen buchhandlung.

Catani, M., Howard, R. J., Pajevic, S., and Jones, D. K. (2002). Virtual in vivo interactive dissection of white matter fasciculi in the human brain. Neuroimage 17, 77-94. doi: 10.1006/nimg.2002.1136

Catani, M., Jones, D. K., Donato, R., and Ffytche, D. H. (2003). Occipito-temporal connections in the human brain. Brain 126, 2093-2107. doi: 10.1093/brain/ awg203

Cheung, V., Cheung, C., McAlonan, G. M., Deng, Y., Wong, J. G., Yip, L., et al. (2008). A diffusion tensor imaging study of structural dysconnectivity in nevermedicated, first-episode schizophrenia. Psychol. Med. 38, 877-885. doi: 10.1017/ S0033291707001808

Coello, A. F., Duvaux, S., De Benedictis, A., Matsuda, R., and Duffau, H. (2013). Involvement of the right inferior longitudinal fascicle in visual hemiagnosia: a brain stimulation mapping study: case report. J. Neurosurg. 118, 202-205. doi: 10.3171/2012.10.JNS12527

Corrivetti, F., Herbet, G., Moritz-Gasser, S., and Duffau, H. (2017). Prosopagnosia induced by a left anterior temporal lobectomy following a right temporooccipital resection in a multicentric diffuse low-grade glioma. World Neurosurg. 97, 756.e1-756.e5. doi: 10.1016/j.wneu.2016.10.025

Crespi, C., Cerami, C., Dodich, A., Canessa, N., Arpone, M., Iannaccone, S., et al. (2014). Microstructural white matter correlates of emotion recognition impairment in amyotrophic lateral sclerosis. Cortex 53, 1-8. doi: 10.1016/j. cortex.2014.01.002

D’Anna, L., Mesulam, M. M., De Schotten, M. T., Dell'Acqua, F., Murphy, D., Wieneke, C., et al. (2016). Frontotemporal networks and behavioral symptoms in primary progressive aphasia. Neurology 86, 1393-1399. doi: 10.1212/WNL. 0000000000002579

Davis, K. L., Stewart, D. G., Friedman, J. I., Buchsbaum, M., Harvey, P. D., Hof, P. R., et al. (2003). White matter changes in schizophrenia: evidence for myelinrelated dysfunction. Arch. Gen. Psychiatry 60, 443-456. doi: 10.1001/archpsyc. 60.5.443

Dawson, G., Webb, S. J., Carver, L., Panagiotides, H., and McPartland, J. (2004). Young children with autism show atypical brain responses to fearful versus neutral facial expressions of emotion. Dev. Sci. 7, 340-359. doi: 10.1111/j.14677687.2004.00352.x

De Benedictis, A., Duffau, H., Paradiso, B., Grandi, E., Balbi, S., Granieri, E., et al. (2014). Anatomo-functional study of the temporo-parieto-occipital region: dissection, tractographic and brain mapping evidence from a neurosurgical perspective. J. Anat. 225, 132-151. doi: 10.1111/joa.12204
Dehaene, S., and Cohen, L. (2011). The unique role of the visual word form area in reading. Trends Cogn. Sci. 15, 254-262. doi: 10.1016/j.tics.2011.04.003

Dehaene, S., Le Clec'H, G., Poline, J.-B., Le Bihan, D., and Cohen, L. (2002). The visual word form area: a prelexical representation of visual words in the Fusiform gyrus. Neuroreport 13, 321-325. doi: 10.1097/00001756-20020304000015

Dejerine, J., and Dejerine-Klumpke, A. (1895). Anatomie des Centres Nerveux. Paris: Rueff.

Dennis, E. L., and Thompson, P. M. (2013). Typical and atypical brain development: a review of neuroimaging studies. Dialogues Clin. Neurosci. 15, 359-384.

Dick, A. S., Bernal, B., and Tremblay, P. (2014). The language connectome: new pathways, new concepts. Neuroscientist 20, 453-467. doi: 10.1177/ 1073858413513502

Douaud, G., Smith, S., Jenkinson, M., Behrens, T., Johansen-Berg, H., Vickers, J., et al. (2007). Anatomically related grey and white matter abnormalities in adolescent-onset schizophrenia. Brain 130, 2375-2386. doi: 10.1093/brain/ awm184

Drane, D. L., Ojemann, J. G., Phatak, V., Loring, D. W., Gross, R. E., Hebb, A. O., et al. (2013). Famous face identification in temporal lobe epilepsy: support for a multimodal integration model of semantic memory. Cortex 49, 1648-1667. doi: 10.1016/j.cortex.2012.08.009

Duan, Y., Norcia, A. M., Yeatman, J. D., and Mezer, A. (2015). The structural properties of major white matter tracts in strabismic amblyopia. Invest. Ophthalmol. Vis. Sci. 56, 5152-5160. doi: 10.1167/iovs.15-17097

Dubois, J., Dehaene-Lambertz, G., Kulikova, S., Poupon, C., Hüppi, P. S., and Hertz-Pannier, L. (2014). The early development of brain white matter: a review of imaging studies in fetuses, newborns and infants. Neuroscience 276, 48-71. doi: 10.1016/j.neuroscience.2013.12.044

Dubois, J., Dehaene-Lambertz, G., Perrin, M., Mangin, J.-F., Cointepas, Y., Duchesnay, E., et al. (2008). Asynchrony of the early maturation of white matter bundles in healthy infants: quantitative landmarks revealed noninvasively by diffusion tensor imaging. Hum. Brain Mapp. 29, 14-27. doi: 10.1002/hbm. 20363

Duffau, H. (2005). Lessons from brain mapping in surgery for low-grade glioma: insights into associations between tumour and brain plasticity. Lancet Neurol. 4, 476-486. doi: 10.1016/S1474-4422(05)70140-X

Duffau, H., and Capelle, L. (2004). Preferential brain locations of low-grade gliomas. Cancer 100, 2622-2626. doi: 10.1002/cncr.20297

Duffau, H., Herbet, G., and Moritz-Gasser, S. (2013). Toward a pluri-component, multimodal, and dynamic organization of the ventral semantic stream in humans: lessons from stimulation mapping in awake patients. Front. Syst. Neurosci. 7:44. doi: 10.3389/fnsys.2013.00044

Epelbaum, S., Pinel, P., Gaillard, R., Delmaire, C., Perrin, M., Dupont, S., et al. (2008). Pure alexia as a disconnection syndrome: new diffusion imaging evidence for an old concept. Cortex 44, 962-974. doi: 10.1016/j.cortex.2008. 05.003

Feinberg, T. E., Schindler, R. J., Ochoa, E., Kwan, P. C., and Farah, M. J. (1994). Associative visual agnosia and alexia without prosopagnosia. Cortex 30, 395-411. doi: 10.1016/S0010-9452(13)80337-1

Feldman, H. M., Lee, E. S., Yeatman, J. D., and Yeom, K. W. (2012). Language and reading skills in school-aged children and adolescents born preterm are associated with white matter properties on diffusion tensor imaging. Neuropsychologia 50, 3348-3362. doi: 10.1016/j.neuropsychologia.2012. 10.014

Fernández-Miranda, J. C., Rhoton, A. L. Jr., Álvarez-Linera, J., Kakizawa, Y., Choi, C., and de Oliveira, E. P. (2008). Three-dimensional microsurgical and tractographic anatomy of the white matter of the human brain. Neurosurgery 62, SHC989-SHC1028. doi: 10.1227/01.neu.0000333767.05328.49

Fischer, D. B., Perez, D. L., Prasad, S., Rigolo, L., O’Donnell, L., Acar, D., et al. (2016). Right inferior longitudinal fasciculus lesions disrupt visual-emotional integration. Soc. Cogn. Affect. Neurosci. 11, 945-951. doi: 10.1093/scan/nsw011

Friedman, J. I., Tang, C., Carpenter, D., Buchsbaum, M., Schmeidler, J., Flanagan, L., et al. (2008). Diffusion tensor imaging findings in first-episode and chronic schizophrenia patients. Am. J. Psychiatry 165, 1024-1032. doi: 10.1176/appi.ajp.2008.07101640

Gaillard, R., Naccache, L., Pinel, P., Clémenceau, S., Volle, E., Hasboun, D., et al. (2006). Direct intracranial, FMRI, and lesion evidence for the causal role of left 
inferotemporal cortex in reading. Neuron 50, 191-204. doi: 10.1016/j.neuron. 2006.03.031

Genova, H. M., Rajagopalan, V., Chiaravalloti, N., Binder, A., Deluca, J., and Lengenfelder, J. (2015). Facial affect recognition linked to damage in specific white matter tracts in traumatic brain injury. Soc. Neurosci. 10, 27-34. doi: 10.1080/17470919.2014.959618

Gil-Robles, S., Carvallo, A., Jimenez, M., del, M., Gomez Caicoya, A., Martinez, R., et al. (2013). Double dissociation between visual recognition and picture naming: a study of the visual language connectivity using tractography and brain stimulation. Neurosurgery 72, 678-686. doi: 10.1227/ NEU.0b013e318282a361

Gomez, J., Pestilli, F., Witthoft, N., Golarai, G., Liberman, A., Poltoratski, S., et al. (2015). Functionally defined white matter reveals segregated pathways in human ventral temporal cortex associated with categoryspecific processing. Neuron 85, 216-227. doi: 10.1016/j.neuron.2014. 12.027

Gratiolet, P. (1839). Anatomie Comparée du Système Nerveux, Vol. 2. Paris: Chez J.-B. Baillière.

Grill-Spector, K., Weiner, K. S., Kay, K., and Gomez, J. (2017). The functional neuroanatomy of human face perception. Annu. Rev. Vis. Sci. 3, 167-196. doi: 10.1146/annurev-vision-102016-061214

Grossi, D., Soricelli, A., Ponari, M., Salvatore, E., Quarantelli, M., Prinster, A., et al. (2014). Structural connectivity in a single case of progressive prosopagnosia: the role of the right inferior longitudinal fasciculus. Cortex 56, 111-120. doi: 10.1016/j.cortex.2012.09.010

Habib, M. (1986). Visual hypoemotionality and prosopagnosia associated with right temporal lobe isolation. Neuropsychologia 24, 577-582. doi: 10.1016/00283932(86)90101-6

Hasan, K. M., Kamali, A., Abid, H., Kramer, L. A., Fletcher, J. M., and Ewing-Cobbs, L. (2010). Quantification of the spatiotemporal microstructural organization of the human brain association, projection and commissural pathways across the lifespan using diffusion tensor tractography. Brain Struct. Funct. 214, 361-373. doi: 10.1007/s00429-009-0238-0

Herbet, G., Maheu, M., Costi, E., Lafargue, G., and Duffau, H. (2016a). Mapping neuroplastic potential in brain-damaged patients. Brain 139, 829-844. doi: 10.1093/brain/awv394

Herbet, G., Moritz-Gasser, S., Boiseau, M., Duvaux, S., Cochereau, J., and Duffau, H. (2016b). Converging evidence for a cortico-subcortical network mediating lexical retrieval. Brain 139, 3007-3021. doi: 10.1093/brain/aww220

Herbet, G., Moritz-Gasser, S., Lemaitre, A.-L., Almairac, F., and Duffau, H. (2018). Functional compensation of the left inferior longitudinal fasciculus for picture naming. Cogn. Neuropsychol. doi: 10.1080/02643294.2018.1477749 [Epub ahead of print].

Hermoye, L., Saint-Martin, C., Cosnard, G., Lee, S.-K., Kim, J., Nassogne, M.C., et al. (2006). Pediatric diffusion tensor imaging: normal database and observation of the white matter maturation in early childhood. Neuroimage 29, 493-504. doi: 10.1016/j.neuroimage.2005.08.017

Hillis, A. E., Newhart, M., Heidler, J., Barker, P., Herskovits, E., and Degaonkar, M. (2005). The roles of the "visual word form area" in reading. Neuroimage 24, 548-559. doi: 10.1016/j.neuroimage.2004.08.026

Hodgetts, C. J., Postans, M., Shine, J. P., Jones, D. K., Lawrence, A. D., and Graham, K. S. (2015). Dissociable roles of the inferior longitudinal fasciculus and fornix in face and place perception. eLife 4:e07902. doi: 10.7554/eLife.07902

Hodgetts, C. J., Postans, M., Warne, N., Varnava, A., Lawrence, A. D., and Graham, K. S. (2017). Distinct contributions of the fornix and inferior longitudinal fasciculus to episodic and semantic autobiographical memory. Cortex 94, 1-14. doi: 10.1016/j.cortex.2017.05.010

Horowitz-Kraus, T., Wang, Y., Plante, E., and Holland, S. K. (2014). Involvement of the right hemisphere in reading comprehension: a DTI study. Brain Res. 1582, 34-44. doi: 10.1016/j.brainres.2014.05.034

Jalbrzikowski, M., Villalon-Reina, J. E., Karlsgodt, K. H., Senturk, D., Chow, C., Thompson, P. M., et al. (2014). Altered white matter microstructure is associated with social cognition and psychotic symptoms in 22q11. 2 microdeletion syndrome. Front. Behav. Neurosci. 8:393. doi: 10.3389/fnbeh. 2014.00393

Jiang, W., Shi, F., Liu, H., Li, G., Ding, Z., Shen, H., et al. (2017). Reduced white matter integrity in antisocial personality disorder: a diffusion tensor imaging study. Sci. Rep. 7:43002. doi: 10.1038/srep43002
Kamali, A., Hasan, K. M., Adapa, P., Razmandi, A., Keser, Z., Lincoln, J., et al. (2014). Distinguishing and quantification of the human visual pathways using high-spatial-resolution diffusion tensor tractography. Magn. Reson. Imaging 32, 796-803. doi: 10.1016/j.mri.2014.04.002

Kanaan, R., Barker, G., Brammer, M., Giampietro, V., Shergill, S., Woolley, J., et al. (2009). White matter microstructure in schizophrenia: effects of disorder, duration and medication. Br. J. Psychiatry 194, 236-242. doi: 10.1192/bjp.bp. 108.054320

Kawahata, N., and Nagata, K. (1989). A case of associative visual agnosia: neuropsychological findings and theoretical considerations. J. Clin. Exp. Neuropsychol. 11, 645-664. doi: 10.1080/01688638908400922

Kelly, S., Jahanshad, N., Zalesky, A., Kochunov, P., Agartz, I., Alloza, C., et al. (2017). Widespread white matter microstructural differences in schizophrenia across 4322 individuals: results from the ENIGMA Schizophrenia DTI Working Group. Mol. Psychiatry 23, 1261-1269. doi: 10.1038/mp.2017.170

Keser, Z., Ucisik-Keser, F. E., and Hasan, K. M. (2016). Quantitative mapping of human brain vertical-occipital fasciculus. J. Neuroimaging 26, 188-193. doi: $10.1111 /$ jon. 12268

Kochunov, P., Coyle, T. R., Rowland, L. M., Jahanshad, N., Thompson, P. M., and Hong, E. (2017). "New insight in white matter and core cognitive deficits in schizophrenia," in Neuropsychopharmacology, ed. W. A. Carlezon (London: Nature Publishing Group), s603-s603.

Koldewyn, K., Yendiki, A., Weigelt, S., Gweon, H., Julian, J., Richardson, H., et al. (2014). Differences in the right inferior longitudinal fasciculus but no general disruption of white matter tracts in children with autism spectrum disorder. Proc. Natl. Acad. Sci. U.S.A. 111, 1981-1986. doi: 10.1073/pnas.1324037111

Kubicki, M., Park, H., Westin, C.-F., Nestor, P. G., Mulkern, R. V., Maier, S. E., et al. (2005). DTI and MTR abnormalities in schizophrenia: analysis of white matter integrity. Neuroimage 26, 1109-1118. doi: 10.1016/j.neuroimage.2005.03.026

Lambon Ralph, M., Jefferies, E., Patterson, K., and Rogers, T. T. (2017). The neural and computational bases of semantic cognition. Nat. Rev. Neurosci. 18, 42-55. doi: $10.1038 /$ nrn.2016.150

Lambon Ralph, M. A. (2014). Neurocognitive insights on conceptual knowledge and its breakdown. Philos. Trans. R. Soc. Lond. B Biol. Sci. 369:20120392. doi: $10.1098 /$ rstb.2012.0392

Lambon Ralph, M. A., Cipolotti, L., Manes, F., and Patterson, K. (2010). Taking both sides: do unilateral anterior temporal lobe lesions disrupt semantic memory? Brain 133, 3243-3255. doi: 10.1093/brain/awq264

Latini, F. (2015). New insights in the limbic modulation of visual inputs: the role of the inferior longitudinal fasciculus and the Li-Am bundle. Neurosurg. Rev. 38, 179-190. doi: 10.1007/s10143-014-0583-1

Latini, F., Mårtensson, J., Larsson, E.-M., Fredrikson, M., Åhs, F., Hjortberg, M., et al. (2017). Segmentation of the inferior longitudinal fasciculus in the human brain: a white matter dissection and diffusion tensor tractography study. Brain Res. 1675, 102-115. doi: 10.1016/j.brainres.2017.09.005

Lebel, C., and Beaulieu, C. (2011). Longitudinal development of human brain wiring continues from childhood into adulthood. J. Neurosci. 31, 10937-10947. doi: 10.1523/JNEUROSCI.5302-10.2011

Lebel, C., and Deoni, S. (2018). The development of brain white matter microstructure. Neuroimage doi: 10.1016/j.neuroimage.2017.12.097 [Epub ahead of print].

Lebel, C., Gee, M., Camicioli, R., Wieler, M., Martin, W., and Beaulieu, C. (2012). Diffusion tensor imaging of white matter tract evolution over the lifespan. Neuroimage 60, 340-352. doi: 10.1016/j.neuroimage.2011.11.094

Lebel, C., Walker, L., Leemans, A., Phillips, L., and Beaulieu, C. (2008). Microstructural maturation of the human brain from childhood to adulthood. Neuroimage 40, 1044-1055. doi: 10.1016/j.neuroimage.2007. 12.053

Lee, S.-H., Kubicki, M., Asami, T., Seidman, L. J., Goldstein, J. M., MesholamGately, R. I., et al. (2013). Extensive white matter abnormalities in patients with first-episode schizophrenia: a diffusion tensor imaging (DTI) study. Schizophr. Res. 143, 231-238. doi: 10.1016/j.schres.2012.11.029

Lee Masson, H., Kang, H., Petit, L., and Wallraven, C. (2017a). Neuroanatomical correlates of haptic object processing: combined evidence from tractography and functional neuroimaging. Brain Struct. Funct. 223, 619-633. doi: 10.1007/ s00429-017-1510-3

Lee Masson, H., Wallraven, C., and Petit, L. (2017b). "Can touch this": crossmodal shape categorization performance is associated with microstructural 
characteristics of white matter association pathways. Hum. Brain Mapp. 38, 842-854. doi: 10.1002/hbm.23422

Lopera, F., and Ardila, A. (1992). Prosopamnesia and visuolimbic disconnection syndrome: a case study. Neuropsychology 6, 3-12. doi: 10.1037/0894-4105.6.1.3

Mandelli, M. L., Caverzasi, E., Binney, R. J., Henry, M. L., Lobach, I., Block, N., et al. (2014). Frontal white matter tracts sustaining speech production in primary progressive aphasia. J. Neurosci. 34, 9754-9767. doi: 10.1523/JNEUROSCI. 3464-13.2014

Mandonnet, E., Gatignol, P., and Duffau, H. (2009). Evidence for an occipito-temporal tract underlying visual recognition in picture naming. Clin. Neurol. Neurosurg. 111, 601-605. doi: 10.1016/j.clineuro.2009. 03.007

Mandonnet, E., Nouet, A., Gatignol, P., Capelle, L., and Duffau, H. (2007). Does the left inferior longitudinal fasciculus play a role in language? A brain stimulation study. Brain 130, 623-629. doi: 10.1093/brain/awl361

Marcotte, K., Graham, N. L., Fraser, K. C., Meltzer, J. A., Tang-Wai, D. F., Chow, T. W., et al. (2017). White matter disruption and connected speech in nonfluent and semantic variants of primary progressive aphasia. Dement. Geriatr. Cogn. Dis. Extra 7, 52-73. doi: 10.1159/000456710

Marstaller, L., Burianová, H., and Reutens, D. C. (2016). Individual differences in structural and functional connectivity predict speed of emotion discrimination. Cortex 85, 65-74. doi: 10.1016/j.cortex.2016.10.001

Martino, J., Brogna, C., Robles, S. G., Vergani, F., and Duffau, H. (2010). Anatomic dissection of the inferior fronto-occipital fasciculus revisited in the lights of brain stimulation data. Cortex 46, 691-699. doi: 10.1016/j.cortex.2009.07.015

Martino, J., De Witt Hamer, P. C., Berger, M. S., Lawton, M. T., Arnold, C. M., de Lucas, E. M., et al. (2013). Analysis of the subcomponents and cortical terminations of the perisylvian superior longitudinal fasciculus: a fiber dissection and DTI tractography study. Brain Struct. Funct. 218, 105-121. doi: 10.1007/s00429-012-0386-5

McDonald, C. R., Leyden, K. M., Hagler, D. J., Kucukboyaci, N. E., Kemmotsu, N., Tecoma, E. S., et al. (2014). White matter microstructure complements morphometry for predicting verbal memory in epilepsy. Cortex 58, 139-150. doi: 10.1016/j.cortex.2014.05.014

McKinnon, E. T., Fridriksson, J., Glenn, G. R., Jensen, J. H., Helpern, J. A., Basilakos, A., et al. (2017). Structural plasticity of the ventral stream and aphasia recovery. Ann. Neurol. 82, 147-151. doi: 10.1002/ana. 24983

Mehta, S., Inoue, K., Rudrauf, D., Damasio, H., Tranel, D., and Grabowski, T. (2016). Segregation of anterior temporal regions critical for retrieving names of unique and non-unique entities reflects underlying long-range connectivity. Cortex 75, 1-19. doi: 10.1016/j.cortex.2015.10.020

Meichtry, J. R., Cazzoli, D., Chaves, S., Arx, S., Pflugshaupt, T., Kalla, R., et al. (2017). Pure optic ataxia and visual hemiagnosia-extending the dual visual hypothesis. J. Neuropsychol. 12, 271-290. doi: 10.1111/jnp. 12119

Meynert, T. (1865). Anatomie der Hirnrinde und ihre Verbindungsbahnen mit den Empfindenden Oberflachen und den Bewegenden Massen. Erlangen: Leidesdorf's Lehrbuch der psychischen Krankheiten.

Migliaccio, R., Agosta, F., Scola, E., Magnani, G., Cappa, S. F., Pagani, E., et al. (2012). Ventral and dorsal visual streams in posterior cortical atrophy: a DT MRI study. Neurobiol. Aging 33, 2572-2584. doi: 10.1016/j.neurobiolaging. 2011.12.025

Milner, A. D., and Goodale, M. A. (1995). Oxford Psychology Series, No. 27. The Visual Brain in Action. New York, NY: Oxford University Press.

Mori, S., Kaufmann, W. E., Davatzikos, C., Stieltjes, B., Amodei, L., Fredericksen, K., et al. (2002). Imaging cortical association tracts in the human brain using diffusion-tensor-based axonal tracking. Magn. Reson. Med. 47, 215-223. doi: 10.1002/mrm.10074

Moritz-Gasser, S., Herbet, G., and Duffau, H. (2013). Mapping the connectivity underlying multimodal (verbal and non-verbal) semantic processing: a brain electrostimulation study. Neuropsychologia 51, 1814-1822. doi: 10.1016/j. neuropsychologia.2013.06.007

Naigles, L. R., Johnson, R., Mastergeorge, A., Ozonoff, S., Rogers, S. J., Amaral, D. G., et al. (2017). Neural correlates of language variability in preschool-aged boys with autism spectrum disorder. Autism Res. 10, 1107-1119. doi: 10.1002/ aur.1756
Norkett, E. M., Lincoln, S. H., Gonzalez-Heydrich, J., and D’Angelo, E. J. (2017). Social cognitive impairment in 22q11 deletion syndrome: a review. Psychiatry Res. 253, 99-106. doi: 10.1016/j.psychres.2017.01.103

Olszewski, A. K., Kikinis, Z., Gonzalez, C. S., Coman, I. L., Makris, N., Gong, X., et al. (2017). The social brain network in 22q11. 2 deletion syndrome: a diffusion tensor imaging study. Behav. Brain Funct. 13:4. doi: 10.1186/s12993-017-0 $122-7$

Ortibus, E. L. S., Verhoeven, J., Sunaert, S., Casteels, I., De Cock, P., and Lagae, L. (2012). Integrity of the inferior longitudinal fasciculus and impaired object recognition in children: a diffusion tensor imaging study. Dev. Med. Child Neurol. 54, 38-43. doi: 10.1111/j.1469-8749.2011.04147.x

Padula, M. C., Scariati, E., Schaer, M., Sandini, C., Ottet, M. C., Schneider, M., et al. (2017). Altered structural network architecture is predictive of the presence of psychotic symptoms in patients with 22q11. 2 deletion syndrome. Neuroimage 16, 142-150. doi: 10.1016/j.nicl.2017.07.023

Panesar, S. S., Yeh, F.-C., Jacquesson, T., Hula, W., and Fernandez-Miranda, J. C. (2018). A quantitative tractography study into the connectivity, segmentation and laterality of the human inferior Longitudinal Fasciculus. Front. Neuroanat. 12:47. doi: $10.3389 /$ fnana.2018.00047

Perez, D., Prasad, S., Acar, D., Meadows, M.-E., Golby, A., and Dworetzky, B. (2014). Visual hypoemotionality (Secondary Visual Derealization) in a patient with a right posterior temporoparietal lesion (P2. 154). Neurology 82, 154.

Philippi, C. L., Mehta, S., Grabowski, T., Adolphs, R., and Rudrauf, D. (2009). Damage to association fiber tracts impairs recognition of the facial expression of emotion. J. Neurosci. 29, 15089-15099. doi: 10.1523/JNEUROSCI.0796-09.2009

Phillips, O. R., Nuechterlein, K. H., Clark, K. A., Hamilton, L. S., Asarnow, R. F., Hageman, N. S., et al. (2009). Fiber tractography reveals disruption of temporal lobe white matter tracts in schizophrenia. Schizophr. Res. 107, 30-38. doi: 10.1016/j.schres.2008.10.019

Price, G., Cercignani, M., Parker, G. J., Altmann, D. R., Barnes, T. R., Barker, G. J., et al. (2007). Abnormal brain connectivity in first-episode psychosis: a diffusion MRI tractography study of the corpus callosum. Neuroimage 35, 458-466. doi: 10.1016/j.neuroimage.2006.12.019

Reil, J. C. (1812). Nachträge zur anatomie des grossen und kleinen Gehirns. Arch. Physiol. 11, 345-376.

Rice, G. E., Hoffman, P., Ralph, L., and Matthew, A. (2015). Graded specialization within and between the anterior temporal lobes. Ann. N. Y. Acad. Sci. 1359, 84-97. doi: 10.1111/nyas.12951

Riley, J. D., Franklin, D. L., Choi, V., Kim, R. C., Binder, D. K., Cramer, S. C., et al. (2010). Altered white matter integrity in temporal lobe epilepsy: association with cognitive and clinical profiles. Epilepsia 51, 536-545. doi: 10.1111/j.15281167.2009.02508.x

Ripollés, P., Biel, D., Peñaloza, C., Kaufmann, J., Marco-Pallarés, J., Noesselt, T., et al. (2017). Strength of temporal white matter pathways predicts semantic learning. J. Neurosci. 37, 11101-11113. doi: 10.1523/JNEUROSCI.1720-17.2017

Rose, S. A., Feldman, J. F., and Jankowski, J. J. (2004). Infant visual recognition memory. Dev. Rev. 24, 74-100. doi: 10.1016/j.dr.2003.09.004

Ross, E. D. (2008). Sensory-specific amnesia and hypoemotionality in humans and monkeys: gateway for developing a hodology of memory. Cortex 44, 1010-1022. doi: 10.1016/j.cortex.2008.02.002

Sachs, H. (1992). Das Hemisphärenmark des Menschlichen Grosshirns: Der Hinterhauptlappen/von Heinrich Sachs. Washington, DC: G. Thieme.

Sarubbo, S., De Benedictis, A., Maldonado, I. L., Basso, G., and Duffau, H. (2013). Frontal terminations for the inferior fronto-occipital fascicle: anatomical dissection, DTI study and functional considerations on a multi-component bundle. Brain Struct. Funct. 218, 21-37. doi: 10.1007/s00429-011-0372-3

Saur, D., Kreher, B. W., Schnell, S., Kümmerer, D., Kellmeyer, P., Vry, M.-S., et al. (2008). Ventral and dorsal pathways for language. Proc. Natl. Acad. Sci. U.S.A. 105, 18035-18040. doi: 10.1073/pnas.0805234105

Scariati, E., Padula, M. C., Schaer, M., and Eliez, S. (2016). Long-range dysconnectivity in frontal and midline structures is associated to psychosis in 22q11. 2 deletion syndrome. J. Neural Transm. 123, 823-839. doi: 10.1007/ s00702-016-1548-z

Schlaffke, L., Leemans, A., Schweizer, L. M., Ocklenburg, S., and SchmidtWilcke, T. (2017). Learning morse code alters microstructural properties in the inferior longitudinal fasciculus: a DTI study. Front. Hum. Neurosci. 11:383. doi: 10.3389/fnhum.2017.00383 
Seitz, J., Zuo, J. X., Lyall, A. E., Makris, N., Kikinis, Z., Bouix, S., et al. (2016). Tractography analysis of 5 white matter bundles and their clinical and cognitive correlates in early-course schizophrenia. Schizophr. Bull. 42, 762-771. doi: $10.1093 /$ schbul/sbv171

Shinoura, N., Suzuki, Y., Tsukada, M., Katsuki, S., Yamada, R., Tabei, Y., et al. (2007). Impairment of inferior longitudinal fasciculus plays a role in visual memory disturbance. Neurocase 13, 127-130. doi: 10.1080/13554790701399254

Shinoura, N., Suzuki, Y., Tsukada, M., Yoshida, M., Yamada, R., Tabei, Y., et al. (2010). Deficits in the left inferior longitudinal fasciculus results in impairments in object naming. Neurocase 16, 135-139. doi: 10.1080/13554790903329174

Sierra, M., and Berrios, G. E. (1998). Depersonalization: neurobiological perspectives. Biol. Psychiatry 44, 898-908. doi: 10.1016/S0006-3223(98)00015-8

Song, S., Garrido, L., Nagy, Z., Mohammadi, S., Steel, A., Driver, J., et al. (2015). Local but not long-range microstructural differences of the ventral temporal cortex in developmental prosopagnosia. Neuropsychologia 78, 195-206. doi: 10.1016/j.neuropsychologia.2015.10.010

Tavor, I., Yablonski, M., Mezer, A., Rom, S., Assaf, Y., and Yovel, G. (2014). Separate parts of occipito-temporal white matter fibers are associated with recognition of faces and places. Neuroimage 86, 123-130. doi: 10.1016/j.neuroimage.2013. 07.085

Thiebaut de Schotten, M., Dell'Acqua, F., Forkel, S. J., Simmons, A., Vergani, F., Murphy, D. G., et al. (2011). A lateralized brain network for visuospatial attention. Nat. Neurosci. 14, 1245-1246. doi: 10.1038/nn.2905

Thomas, C., Avidan, G., Humphreys, K., Jung, K., Gao, F., and Behrmann, M. (2009). Reduced structural connectivity in ventral visual cortex in congenital prosopagnosia. Nat. Neurosci. 12, 29-31. doi: 10.1038/nn.2224

Tsapkini, K., and Rapp, B. (2010). The orthography-specific functions of the left fusiform gyrus: evidence of modality and category specificity. Cortex 46, 185-205. doi: 10.1016/j.cortex.2009.02.025

Tu, S., Leyton, C. E., Hodges, J. R., Piguet, O., and Hornberger, M. (2016). Divergent longitudinal propagation of white matter degradation in logopenic and semantic variants of primary progressive aphasia. J. of Alzheimers Dis. 49, 853-861. doi: 10.3233/JAD-150626

Turkeltaub, P. E., Goldberg, E. M., Postman-Caucheteux, W. A., Palovcak, M., Quinn, C., Cantor, C., et al. (2014). Alexia due to ischemic stroke of the visual word form area. Neurocase 20, 230-235. doi: 10.1080/13554794.2013.770873

Turken, U., and Dronkers, N. F. (2011). The neural architecture of the language comprehension network: converging evidence from lesion and connectivity analyses. Front. Syst. Neurosci. 5:1. doi: 10.3389/fnsys.2011.00001

Tusa, R. J., and Ungerleider, L. G. (1985). The inferior longitudinal fasciculus: a reexamination in humans and monkeys. Ann. Neurol. 18, 583-591. doi: 10.1002/ana.410180512

Tylee, D. S., Kikinis, Z., Quinn, T. P., Antshel, K. M., Fremont, W., Tahir, M. A., et al. (2017). Machine-learning classification of 22q11. 2 deletion syndrome: a diffusion tensor imaging study. Neuroimage 15, 832-842. doi: 10.1016/j.nicl. 2017.04.029

Unger, A., Alm, K. H., Collins, J. A., O’Leary, J. M., and Olson, I. R. (2016). Variation in white matter connectivity predicts the ability to remember faces and discriminate their emotions. J. Int. Neuropsychol. Soc. 22, 180-190. doi: $10.1017 /$ S1355617715001009
Ungerleider, L. G., and Haxby, J. V. (1994). 'What'and 'where'in the human brain. Curr. Opin. Neurobiol. 4, 157-165. doi: 10.1016/0959-4388(94)90066-3

Visser, M., Jefferies, E., and Ralph, M. L. (2010). Semantic processing in the anterior temporal lobes: a meta-analysis of the functional neuroimaging literature. J. Cogn. Neurosci. 22, 1083-1094. doi: 10.1162/jocn.2009.21309

Wakana, S., Caprihan, A., Panzenboeck, M. M., Fallon, J. H., Perry, M., Gollub, R. L., et al. (2007). Reproducibility of quantitative tractography methods applied to cerebral white matter. Neuroimage 36, 630-644. doi: 10.1016/j. neuroimage.2007.02.049

Wang, Y., Metoki, A., Alm, K. H., and Olson, I. R. (2018). White matter pathways and social cognition. Neurosci. Biobehav. Rev. 90, 350-370. doi: 10.1016/j. neubiorev.2018.04.015

Weigelt, S., Koldewyn, K., and Kanwisher, N. (2012). Face identity recognition in autism spectrum disorders: a review of behavioral studies. Neurosci. Biobehav. Rev. 36, 1060-1084. doi: 10.1016/j.neubiorev.2011.12.008

Weinberger, R., Yi, J., Calkins, M., Guri, Y., McDonald-McGinn, D. M., Emanuel, B. S., et al. (2016). Neurocognitive profile in psychotic versus nonpsychotic individuals with 22q11. 2 deletion syndrome. Eur. Neuropsychopharmacol. 26, 1610-1618. doi: 10.1016/j.euroneuro.2016.08.003

Wernicke, C. (1881). Lehrbuch der Gehirnkrankheiten für Aerzte und Studirende. New York, NY: Fischer.

Wilson, C. L., Babb, T. L., Halgren, E., and Crandall, P. H. (1983). Visual receptive fields and response properties of neurons in human temporal lobe and visual pathways. Brain 106, 473-502. doi: 10.1093/brain/106.2.473

Yeatman, J. D., Dougherty, R. F., Ben-Shachar, M., and Wandell, B. A. (2012). Development of white matter and reading skills. Proc. Natl. Acad. Sci. U.S.A. 109, E3045-E3053. doi: 10.1073/pnas.1206792109

Yeatman, J. D., Weiner, K. S., Pestilli, F., Rokem, A., Mezer, A., and Wandell, B. A. (2014). The vertical occipital fasciculus: a century of controversy resolved by in vivo measurements. Proc. Natl. Acad. Sci. U.S.A. 111, E5214-E5223. doi: 10.1073/pnas.1418503111

Yoshida, S., Oishi, K., Faria, A. V., and Mori, S. (2013). Diffusion tensor imaging of normal brain development. Pediatr. Radiol. 43, 15-27. doi: 10.1007/s00247012-2496-x

Zemmoura, I., Blanchard, E., Raynal, P.-I., Rousselot-Denis, C., Destrieux, C., and Velut, S. (2016). How Klingler's dissection permits exploration of brain structural connectivity? An electron microscopy study of human white matter. Brain Struct. Funct. 221, 2477-2486. doi: 10.1007/s00429-015-1050-7

Conflict of Interest Statement: The authors declare that the research was conducted in the absence of any commercial or financial relationships that could be construed as a potential conflict of interest.

Copyright (c) 2018 Herbet, Zemmoura and Duffau. This is an open-access article distributed under the terms of the Creative Commons Attribution License (CC BY). The use, distribution or reproduction in other forums is permitted, provided the original author(s) and the copyright owner(s) are credited and that the original publication in this journal is cited, in accordance with accepted academic practice. No use, distribution or reproduction is permitted which does not comply with these terms. 